\title{
Da solidão à comunidade ${ }^{1}$ (Round-trip)
}

EDUARDO PELLEJERO²

Somos todos a mesma coisa.

Sempre fui muito solitário. Não é uma impostura. Quando era criança a minha saúde era muito frágil, o que me obrigava muitas vezes a passar longos períodos na cama, longe da rua (que era na minha época a única rede social que existia).

Nesse recolhimento forçado, descobri que a solidão não é necessariamente um deserto. A solidão, pelo contrário, pode ser uma selva. Eu me criei nessa selva. Não estranha, portanto, que me sinta cômodo nela - no alto da noite, na tranquilidade do meu quarto, onde o mundo faz silêncio.

A solidão também não é o isolamento. Maurice Blanchot, que escreveu algumas das coisas mais interessantes sobre a solidão, dizia que, mesmo voltando às costas ao mundo e à história, o solitário (o escritor, porque ele pensava na solidão do escritor) pressupõe sempre o outro (o leitor) como aquele ao qual se dirige a sua solidão - promessa de uma comunidade, não dada, mas sempre por vir.

É verdade que estou aqui para falar da comunidade (e vou fazê-lo já, de imediato), mas antes quero deixar claro por que para mim a comunidade não é primeira, não está dada, mas é segunda, e deve ser construída (a partir de uma aceitação corajosa da solidão). Isso é assim porque a apreensão de certas realidades, de certas coisas fundamentais, não se dá em companhia e, nesse sentido, a solidão constitui um momento essencial da nossa emancipação, isto é, da afirmação da nossa liberdade.

Em torno da pessoa que se encontra a caminho de começar a sentir e a pensar por conta própria, sempre deve existir uma separação dos outros, uma separação que pode ser momentânea ou mesmo virtual, que pode dar-se inclusive em companhia, mas que ninguém pode poupar-se. Alejandra Pizarnik, uma escritora argentina cuja solitária leitura lhes recomendo vivamente, anotava no seu diário (2 de Fevereiro de 1958): "Esta maneira de ser [solitária] me faz perder e ganhar. Perder, enquanto me aprisiona, me impede de enfrentar o mundo. Mas, por outra

\footnotetext{
${ }^{1} \mathrm{O}$ presente texto teve a sua origem em uma intervenção numa das ações formativas de "O mundo inteiro é um palco", organizado pelos "Clowns de Shakespeare", no dia 26 de Setembro de 2016. Os "Clowns de Shakespeare" existem, de fato, desde 1993 e contam já mais de vinte anos de trajetória. Para mais informação sobre o grupo: http://www.clowns.com.br/

${ }^{2}$ Argentino de nascimento, português por adoção, residente no Brasil, apátrida por convicção. Atualmente é professor de Estética Filosófica na Universidade Federal do Rio Grande do Norte, onde desenvolve uma investigação no domínio da filosofia (política) da arte.
} 
parte, no reverso do mundo, onde eu me encontro, veem-se muitas coisas vedadas para os outros" (2012, p. 103).

As pessoas tendem a abreviar tanto quanto possível a solidão, procuram poupar-se da solidão, comprometendo-se completamente em projetos que esgotam o seu tempo e as suas energias, adotando uma posição no mundo; e está bem, eu não quero dizer que os compromissos não sejam importantes, mas chegar ao compromisso depois de ter passado pela solidão nos abre a uma intervenção mais rica, pelo menos na medida em que a solidão é o espaço no qual, na nossa época, se consuma a morte de deus, dando lugar a um verdadeiro laboratório do possível espaço onde, desincorporando a nossa subjetividade das identificações imaginárias que cobram a nossa adesão ao mundo tal como é, podemos pensa-lo tal como não é, isto é, tal como ainda não é, como poderia ser.

Porque ninguém pode fazer a experiência por nós, porque ninguém pode sentir e pensar por nós, a emancipação é necessariamente um caminho solitário. Porém a emancipação quiçá só seja possível e ganhe sentido coletivamente. Os mais interessantes pensadores da emancipação sempre projetaram as suas ideias sobre esse horizonte comum.

Roland Barthes, por exemplo, imaginava uma espécie de utopia menor, na qual aqueles engajados na aventura da emancipação fariam circular as suas experiências, através de textos escritos com prazer, fora de qualquer instância mercantil, sem necessidade de grande difusão, em pequenos grupos, ou entre amizades (1975). O modelo de comunidade de Barthes era o falanstério, essa comunidade idealizada por Charles Fourier, na qual tudo estaria organizado de forma harmônica e descentralizada e onde cada um trabalharia conforme as suas paixões e interesses, a sua vocação e desejo.

Jacques Rancière, pela sua parte, chegará a considerar que o correlato da emancipação intelectual é, necessariamente, uma comunidade emancipada, isto é, "uma comunidade de narradores e tradutores" (2010, p. 28), onde o trabalho poético de tradução da experiência substitui a distinção entre aqueles que atuam e aqueles que olham, entre aqueles que criam e aqueles que contemplam, entre leigos e especialistas - seres, todos, que partilham as mesmas faculdades, as mesmas competências, isto é, igual inteligência.

Como se articulam, em todo caso, a solidão e a comunidade? Como é sequer possível que se relacionem quando a emancipação, e a solidão que é a sua condição, não admitem nenhum pressuposto, nenhum lugar comum? 
Disse já que o comum nunca está dado. Nem a família nem a igreja, nem a nação nem o estado, nem nenhuma das formas de sedimentação do comum fazem outra coisa que confiscar a nossa potência de construir o comum em troca de um acolhimento impossível. O comum deve ser inventado, articulado, agenciado, através de mil gestos, de um trabalho de comunicação sem princípio nem fim, isto é, sem fundamento nem finalidade (nem deus, nem a natureza, nem sequer o homem, podem ser invocados aqui como ponto de partida ou horizonte de chegada).

De resto, se o comum existe, existe de maneira eventual - no sentido em que falamos de um evento, de uma ocasião especial, de uma festa, por exemplo (e lembrem que a forma mais simples de agrupação anarquista, ou, se preferem, de zona autônoma temporária, é, segundo Hakim Bey, a festa). Quero dizer que, se o comum existe, tem a forma de um acontecimento.

Nas sociedades tradicionais, nas chamadas vilas comunitárias, por exemplo, como em alguns lugares da fronteira entre Espanha e Portugal, as pessoas ajudavam umas às outras para atos de necessidade coletiva, de interesse comum: caçar um animal, reparar o telhado duma casa, fazer a colheita ou celebrar o fim do inverno. Se reuniam no centro da vila, se encaminhavam ao lugar onde era necessário, trabalhavam e comiam lado a lado e depois regressavam, cansados e satisfeitos, às suas vidas.

Também nós conhecemos esse tipo de experiências. Juntos, na rua, por exemplo, numa manifestação, sabemos participar de uma forma da comunidade que é em si mesma um acontecimento. As nossas singularidades e as nossas diferenças, e também as nossas solidões, se articulam aí durante o tempo que dura o evento (que pode ser muito breve, como nas passeatas que vivemos nos últimos meses, mas também estender-se no tempo, como no caso das greves gerais ou de certos acontecimentos que deixaram a sua marca na história: Maio de 68, por exemplo). É, também, quiçá, o caso das ocupações, como a ocupação do Garden, que continua, sempre no mesmo lugar, mas sempre cambiante, detrás do edifício do Deart, acolhendo àqueles que se aproximam debaixo de duas mangueiras e dois pés de caju ${ }^{3}$.

$* * *$

Como podem ver, as comunidades eventuais tem uma relação íntima com a festa, mas também se aproximam da comunidade da luta. Sartre dizia que não existem valores absolutos, que não há nada que possamos chamar de absoluto, fora daqueles que lutam junto a nós na trincheira. Aí, a comunidade não é aquilo que

\footnotetext{
3 O "Garden" é um espaço autogestionado por estudantes do Departamento de Artes da UFRN, resultado de uma ocupação que teve lugar durante 2013 - lugar de encontro e de atividades livres que resiste de forma criativa desde então.
} 
luta nem aquilo pelo qual se luta. A comunidade é um efeito da luta, do estar-ladoao-lado ou do estar-aí-incondicionalmente-para-o-outro.

As lutas nas quais nos envolvemos podem ter os mais diversos signos. Ainda consigo lembrar a luta em que se encontravam os Clowns de Shakespeare para existir já faz 16 anos, quando ocupavam um pequeno espaço emprestado pela prefeitura na cidade alta. Também lembro da luta que me uniu, mais de uma década atrás, a um punhado de nômades como eu, em Lisboa, para dar expressão ao que pensávamos, numa revista que nunca chegou a ver o seu segundo número (essa revista se chamava ou se chamaria VLOV!).

Alguns grupos perduram no tempo (na luta), como os Clowns, outros cintilam brevemente e desaparecem, como o nosso, mas independentemente da sua duração, todos os grupos que respeitam a singularidade dos seus integrantes, e o caminho de cada um em prol da emancipação, são eventuais (isso também quer dizer que sempre acabam dando lugar à desagregação, à dissolução, ao devir).

Em todo o caso, o desaparecimento que está prometido até aos nossos projetos mais nobres não é algo que devamos lamentar, porque mesmo sendo muitas vezes vivido sob a forma da tristeza não é algo apenas desmobilizador. Quiçá o fracasso mereça inclusive um lugar entre as artes! Depois de tudo, como as artes, os nossos projetos de comunidade nascem continuamente e continuamente fracassam, mas não deixam de ter efeitos imanentes e incalculáveis em nós.

Como a revolução para Gilles Deleuze, os grupos dos que chegamos a formar parte, constituem nas nossas vidas uma bifurcação, um desvio em relação às leis (inclusive às leis da nossa solidão), e pelo mesmo podem chegar a colocar-nos num estado instável, mas também abrir-nos a novos campos de possíveis. No fundo, um grupo pode ser contrariado, reprimido, atraiçoado ou desfeito, mas comporta sempre qualquer coisa de insuperável (DELEUZE, 2013), uma força de contestação própria da vida poética (DELEUZE, 2002), capaz de deslocar o nosso desejo e de reorganizar a nossa vida, criando novas relações com o corpo, o tempo, a sexualidade, o meio, a cultura, o trabalho, etc.

O comum nunca está dado, mas deve ser sempre inventado. A comunidade não é nunca algo substancial, mas algo que tem a elusiva substância do acontecimento, do devir. Isso não significa que seja um sonho, algo que não se realiza nunca, ou que só se realiza traindo-se; significa, apenas, pensar a comunidade e o comum como plano de imanência ou movimento infinito, na medida em que se conectam com as lutas que travamos como indivíduos e relançam novas lutas cada vez que a anterior é traída (DELEUZE; GUATTARI, 1991). 
Inclusive os mais solitários entre nós, não podemos senão apelar a essas comunidades eventuais sem as quais a luta resulta impossível (e é necessária muita luta, inclusive, ou sobretudo, para tornar possível a criação, o pensamento e a arte). O comum nos falta, ou nos faz falta.

"O artista - escreveu Deleuze - não pode mais que apelar a um povo, tem esta necessidade no mais profundo da sua empresa” (1990, p. 235). Retomava assim uma afirmação de Paul Klee, que na sua Théorie de l'art moderne escrevia: "Achamos as partes, mas ainda não achamos o conjunto. Falta-nos essa última força. Falta-nos um povo que nos acolha. Procuramos esse apoio popular: na Bauhaus [aquele grupo fabuloso, sonhado], começamos com uma comunidade à qual damos tudo o que temos. Não podemos fazer mais" (1998, p. 33).

O comum é algo ao mesmo tempo desejado e inventado, sonhado e produzido. Não é nada sem o nosso compromisso, mas também não depende apenas de nós. Klee e os seus amigos da Bauhaus fizeram tudo o que esteve ao seu alcance para que a comunidade se manifestasse, mas, como sabem, da comunidade só conheceram o seu avesso - o ódio das massas identificadas com o hitlerismo.

Necessitamos do comum, temos que inventar o comum, mas o comum, como o amor, pode ter lugar ou não, pode acontecer ou não. Aqui no Brasil dizem (é uma frase que gosto muito): "pintou um clima". Quando pinta um clima estamos juntos. Não é suficiente estar entre pessoas para estar juntos, é necessário que pinte um clima. Mas o clima é das coisas mais imprevisíveis do mundo e a verdade é que nem sempre nem a maioria das vezes pinta um clima (mas por vezes pinta um clima então é a primavera).

Não sei se conhecem Partner, um dos primeiros filmes de Bernardo Bertolucci. Aí, Giacobbe, um professor de teatro muito tradicional, sai do seu isolamento e devém-outro junto aos seus alunos: altera os limites da sala de aula e empreende um discurso que já não pretende tomar a palavra pelos outros, mas fazer silêncio, ou pelo menos gerar a confusão necessária para que aqueles que não são ouvidos habitualmente possam fazer-se ouvir (trata-se, no fundo, de uma posta em cena). Espera que as circunstâncias e as vontades individuais, a coragem e a inteligência de cada um, façam o resto e conduzam à constituição de uma comunidade de luta, de uma nova força política. Claro que isso não depende apenas dele, depende também de que cada um aceite, por conta e risco, as aventuras da emancipação e devenham, por sua vez, outros com ele, ou junto a ele. É maio de 1968.

Não vou contar o final dessa história, que quiçá vocês próprios sejam capazes de mudar, porque esse encontro continua marcado. Vou contar, melhor, uma história de outro filme, de Los lunes al sol (As segundas ao sol), um filme de Fernando León de Aranoa. Aí, um grupo de operários cessantes que viram fracassar a sua luta contra o capital de todas as formas imagináveis (a traição e o acordo de 
alguns, a condenação e a morte de outros), um grupo muito sofrido, portanto, um grupo perto da desagregação, do próprio fim do grupo, discute se vale de alguma coisa estar-juntos, se constituir-se como grupo e colocar as nossas vidas em comum é algo bom (e muitos acham que não - como digo, estão muito magoados). Então Santa (Javier Bardem), que não foi quem menos perdeu em tudo isso, com uma sensibilidade e uma inteligência comovedoras, diz que, independentemente do que passou, do que aconteceu, para além do modo que correram as coisas, durante o tempo que durou a greve, durante essa interrupção ou entre-tempo no qual nada parece ter acontecido, mas no qual tudo, inclusive cada um deles, foi ou se comportou de um modo diferente, durante esse tempo, diz, estiveram juntos, e isso já ninguém pode tirar-lhes. Isso é verdade.

O êxito de um grupo só reside no próprio acontecimento que constitui estarjuntos: nas vibrações, nos abraços, nas aberturas que deu aos indivíduos no momento em que teve lugar.

O êxito de um grupo é imanente, e consiste nos novos laços que instaura entre nós, ainda quando esses laços não durem mais do que a sua matéria em fusão e muito rapidamente dêem lugar à divisão, à traição, à desaparição (DELEUZE, 1991, p. 167).

Gostaria de acabar com um pequeno texto de um raro e esquecido romance de Vargas Llosa, quem apesar de nunca ter parecido capaz de pensar em grupo, colocou nas palavras de um povo do alto Amazonas estas palavras luminosas, que aquecem o coração de qualquer um, não importa quem:

Temos que aprender isto. Eles chegam sempre onde estamos. Foi assim desde o princípio. Quantas vezes tive que me ir porque chegavam? Desde antes de nascer, parece. E assim será quando eu ir e voltar, se a minha alma não ficar nos mundos de além. Sempre estivemos a ir porque vinham. Em quantos lugares vivi? Quem sabe, mas foram muitos. 'Vamos procurar um lugar tão difícil, tão emaranhado, ao qual nunca chegarão', dizia. 'Ou um lugar aonde, se chegam, não queiram ficar'. Mas eles sempre chegavam e sempre queriam ficar. É coisa sabida. Não há engano. Virão e eu me irei. É mau isso? Será bom, quiçá. Será o nosso destino. Não somos os que caminham? [...] O povo que caminha é agora o meu. Antes, eu caminhava com outro povo e acreditava que era o meu. Não havia nascido ainda. Nasci de verdade desde que ando com vocês. [...] $\mathrm{O}$ sol cai, não termina de cair. Vai e volta, como as almas com sorte. Aquece o mundo. A gente da terra não cai tampouco. Aqui estamos. Eu no meio, vocês rodeando-me. Eu falando, vocês ouvindo. Vivemos, caminhamos. Isso é a felicidade, parece (1987, p. 207 e 212). 


\section{Referências bibliográficas}

BARTHES, Escrever... Para quê? Para Quem?. Lisboa: Edições 70, 1975.

DELEUZE, Gilles. Deux régimes de fous. Paris: Minuit, 2003.

. L'île déserte et autres textes. Paris: Minuit, 2002.

. Pourparlers 1972-1990, Paris: Éditions de Minuit, 1990.

_ _ GUATTARI, Félix. Qu'est-ce que la philosophie? Paris: Éditions de Minuit, 1991.

KLEE, Théorie de l'art moderne, Paris: Gallimard, 1998.

LLOSA, Vargas. El hablador. Barcelona: Planeta, 1987.

PIZARNIK, Alejandra. Diarios. Buenos Aires: Lumen, 2012.

RANCIERE, Jacques. El espectador emancipado, Buenos Aires: Manantial, 2010.

Submissão: 12.10.2016 / Aceite: 28.11.2016 